\title{
Socio-environmental determinants of the delay in the first dental visit: results of two population-based cohort studies in Brazil
}

\author{
A.L.F.H. Soares ${ }^{1}{ }^{1}$, C.C.C. Ribeiro (i) $^{2}$, E.B.A.F. Thomaz ${ }^{3}{ }^{3}$, R.C.S. Queiroz $(10)^{3}$, C.M.C. Alves ${ }^{2}{ }^{2}$,

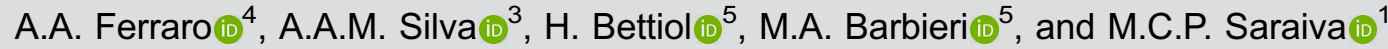 \\ ${ }^{1}$ Departamento de Clínica Infantil, Faculdade de Odontologia de Ribeirão Preto, Universidade de São Paulo, \\ Ribeirão Preto, SP, Brasil \\ ${ }^{2}$ Departamento de Odontologia II, Universidade Federal do Maranhão, São Luís, MA, Brasil \\ ${ }^{3}$ Departamento de Saúde Pública, Universidade Federal do Maranhão, São Luís, MA, Brasil \\ ${ }^{4}$ Departamento de Pediatria, Faculdade de Medicina, Universidade de São Paulo, São Paulo, SP, Brasil \\ ${ }^{5}$ Departamento de Puericultura e Pediatria, Faculdade de Medicina de Ribeirão Preto, Universidade de São Paulo, \\ Ribeirão Preto, SP, Brasil
}

\begin{abstract}
The objective of this study was to describe the timing of the first dental visit and investigate the association of socioeconomic and behavioral factors with dental visit delay among 10/11-year-old children from two live-birth population cohorts with extremely contrasting socioeconomic profiles. Follow-up data (2004-2005) from cohorts of Ribeirão Preto (RP) ( $n=790)$ and São Luís (SL) $(n=673)$ were evaluated. Delay in dental visit was defined as not visiting a dentist before the age of 7 . Covariates included family socioeconomic characteristics, mother-related health behavior, and child-related characteristics. Prevalence ratios with robust standard errors were estimated. In both cohorts, less than $5 \%$ of children had visited a dentist before the age of two and about $35 \%$ of them had not visited a dentist before the age of seven. Lower mother's schooling and lack of private health insurance were associated with the delay in first dental visit for both cohorts. A small number of mother's prenatal care visits and being from a single-father family or a family without parents were only associated in the RP cohort, while having $\geqslant 4$ siblings and lifetime dental pain were associated in the SL cohort. The association with dental pain probably reveals a preventive careseeking behavior. Therefore, the percentage of delayed first dental visit of children was very high even among those with the most educated mothers. Further studies are necessary to analyze recent changes and underlying factors related to access to first dental visit after the implementation of the National Oral Health Policy in 2006.
\end{abstract}

Key words: First dental visit; Epidemiology; Children's oral health; Health service utilization; Cohort study

\section{Introduction}

The American Academy of Pediatric Dentistry (AAPD) recommends that the first dental visit should occur at the time of first tooth eruption and no later than 12 months of age (1). Regardless of the lack of empirical evidence about the best age that a child should first be taken to a dentist and the efficacy of early dental visits (2), these guidelines are based on the premise that early detection and management of oral conditions and anticipatory guidance improve the oral health and well-being of children (3).

In spite of consensus among Dental Associations about the importance of a preventive dental visit in the first year of life, there are only a few studies reporting the timing of a child's first dental visit, with conflicting results about its effects on caries prevention and costs. Among the reasons for these inconsistencies is the difficulty in defining what a preventive dental visit is. Unfortunately, most of the studies trying to address the efficiency of early dental visits are from other countries, such as a series of studies with Medicaid (USA) data from reimbursement records (4-6). The best evidence from these studies was that delaying the first dental visit was associated with future emergency visits and restorative procedures, especially for children at highest risk of dental caries. Although Medicaid studies help us to understand some aspects of the timing of preventive dental visits, they are limited to children from very low income families under the age of five who are continuously enrolled in the program $(4,5)$. We found only a few other population studies addressing the effects of the timing of the first 
dental visit. Ismail and Sohn (7), in a study conducted in Canada in an area covered by universal dental insurance, observed that only $8.4 \%$ of children had visited a dentist before the age of two, with no association with lower levels of dental caries. In that study, $96.9 \%$ of children had been to a dentist by the age of five and the majority of dental visits were preventive ones (92.4\%). In the United Kingdom, where dental insurance is traditionally universal as in Brazil, although most children under the age of five had already seen a dentist $(94 \%)$, only $30 \%$ had a dental visit before the age of two (8). By contrast, in the United States, with a public health system only for those below the poverty line, $46.2 \%$ of children two to five years old had never visited a dentist (9).

In Brazil, a country with a public-private mixed health system where providing free healthcare for all citizens (including oral health care) is an obligation of the State, this percentage is even higher. Despite the great advances in oral health policies, especially with the National Oral Health Policy (NOHP) in Brazil (10), inequalities related to access and utilization of dental services persist $(11,12)$. The latest 2008 Brazilian National Household Survey (13) and National Oral Health Survey (NOHS) (14) showed that 67.2 and $46.8 \%$ of six- and five-year-old children, respectively, had never been to a dentist. Although the absence of dental visits was 1.6 times more likely to be seen among children in the poorest quintile of family income, the percentage was still very high $(47.3 \%)$ among the richest ones. A similar inequality ratio was observed in a population-based cohort study of five-year-old children in the south of Brazil, which also revealed that $63 \%$ of all children had never been to a dentist by that age (15). An interesting finding from that study was that the majority of dental visits for both prevention and treatment were observed among the richest families and that those who sought preventive dental visits had a lower prevalence of dental caries. Although the study addressed the reasons for dental visits, the timing of the first dental visit was restricted to five-year-old children. Considering that only about $30 \%$ of children had been taken to a dentist by the age of five, more information is needed about the timing of the first dental visit throughout childhood and associated factors. Thus, the objective of the present study was to describe the timing of the first dental visit and to explore factors associated with dental visit delay in two live-birth population cohorts with extremely contrasting socioeconomic profiles in Brazil.

\section{Material and Methods}

This study is an analysis of the follow-up data of two live-birth population cohort studies conducted with the same methodology $(16,17)$ by the same research team in Brazil. One cohort was started in 1994 in the city of Ribeirão Preto (RP), situated in one of the wealthiest areas of southeast Brazil (São Paulo State), with a Municipal Human Development Index (MHDI) of 0.855 in 2000
(18) and a population of 461,427 inhabitants in 1994 (19). The other cohort was established in 1997 in the city of São Luís (SL), capital of the State of Maranhão (northeast region), with an MHDI of 0.658 in 2000 (18) and with 781,068 inhabitants in 1997 (20).

The RP cohort included virtually all (99\%) live births that occurred in the city from April to August 1994 and the SL cohort comprised a systematic sample of $96.3 \%$ of all live births occurring in hospitals from March 1997 to February of 1998. Losses were less than 5\% in RP and $6 \%$ in SL, represented mostly by refusal to participate and anticipated discharge from the hospital. Excluding twin births, the final samples for RP and SL were 2,846 and 2,443 participants, respectively. Before discharge from the hospital, children were measured (weight and length), and trained researchers interviewed the mothers. The information collected during the interview comprised socioeconomic and demographic characteristics, mother's health behavior during gestation, and gestational age at childbirth.

Both cohorts were followed-up in 2004/2005 when children were 10/11 years old in RP and 6/7 years old in SL. The follow-up sample was stratified in order to guarantee representativeness of five birth weight groups $(<1,500 \mathrm{~g}$; 1,500-2,499 g; 2,500-2,999 g; 3,000-4,249 g; $\geqslant 4,250 \mathrm{~g}$ ). Low birth weight was oversampled by including all lowbirth weight children and a random sample of $1 / 3$ of those with normal weight in order to guarantee the power of the study, since the major objective of these cohorts was to study the health of low-birth weight and preterm birth children. After the exclusion of stillborn infants and infants who had died in the first year of life, 1,150 and 926 children were sampled for the follow-up, respectively for RP and SL. Reasons for loss to follow-up in RP and SL included migration, death, and refusal to participate. More detailed information on the methods applied to the cohorts can be found elsewhere (21). The final samples represented $69.4 \%(n=790)$ and $72.7 \%(n=673)$ of the eligible samples for RP and SL, respectively. The study was approved by the Research Ethics Committee of the Ribeirão Preto Medical School (HC-FMRP-USP; No. 6828/2004) and of the University Hospital, Federal University of Maranhão, Brazil (No. 060/2005).

Information about age (integer years) at first dental visit was obtained during the follow-up interview. Although age at the first dental visit is a discrete variable, competing motivations for this dental visit (prevention vs treatment need) results in a non-homogeneous outcome precluding its analysis as such, for example, using specific survival analysis. We were interested in knowing why parents delay dental visits to a point that is unacceptable. Only a small percentage of children had seen a dentist before the age of one and most of them had been to a dentist when 3 to 6 years of age. It is expected that, at the latest, a child will be taken to a dentist at the eruption of the first molars if not before for evaluation of pit and fissure sealant need (22). Therefore, we decided to categorize the variables as 
$<7$ and $\geqslant 7$ years old, a cut-off point indicating the maximum age when a family is expected to take their child to a dentist due to the eruption of the first permanent molar. Moreover, by the age of six (before 7), children are required by law to enter the school system, where parents are usually advised to take their children to a dentist. Our outcome definition also permitted us to compare the two cohorts including censored data (those who had not seen a dentist up to the follow-up interview) in the group aged $\geqslant 7$ years. Although an additional cut-off point at 3 years of age was suggested and tested, we are presenting only the analysis with a dichotomous variable $(<7 / \geqslant 7)$ because the final models for both cut-offs were closely similar, except for very large confidence intervals in a multinomial model.

Information on covariates was obtained from the baseline and follow-up interviews. The explanatory variables included in the study followed a conceptual framework based on the Andersen, Davidson, and Baumeister behavior model of health services utilization (23) (Figure 1). In addition, the model for the choice of variables was guided by the most common variables related to access to health services in the literature. Predisposing factors included demographic (child's skin color and mother's age) and social characteristics of the family (mother's schooling, household occupation, family structure, and number of siblings living in the child's household). As stated by Andersen et al. (23), individual social factors are those "determining the status of a person in the community as well as his ability to cope....[ ]. Traditional measures include education, occupation and ethnicity". Enabling factors were represented by the continuity of the child's private health insurance. The need factor was represented by child's oral health (measured as perception by the mother) and lifetime dental pain experience due to dental caries. Health behavior factors included mother's number of prenatal care visits and smoking habit during pregnancy. Household head's occupation was categorized as non-manual, skilled manual, and unskilled manual work. Mother's schooling level was also used as a proxy measure for socioeconomic position instead of family income because of the extremely high percentage of parents/caretakers who did not want to report their income. Mothers schooling level was categorized as incomplete primary school and complete primary, middle and secondary schooling, and bachelor's degree. Family structure was classified based on the presence of both biological parents in a nuclear family, a single mother, a mother with a step-parent, a single father with or without a stepmother, and families without biological parents. Child skin color was categorized as white and others because only about $4 \%$ of mothers designated their children as being black and most of them reported being of mixed color (mulatto). Continuity of health insurance coverage during childhood was constructed from two questions exploring if the child was covered by private health insurance at the age of three, and also in the previous six months of the follow-up.

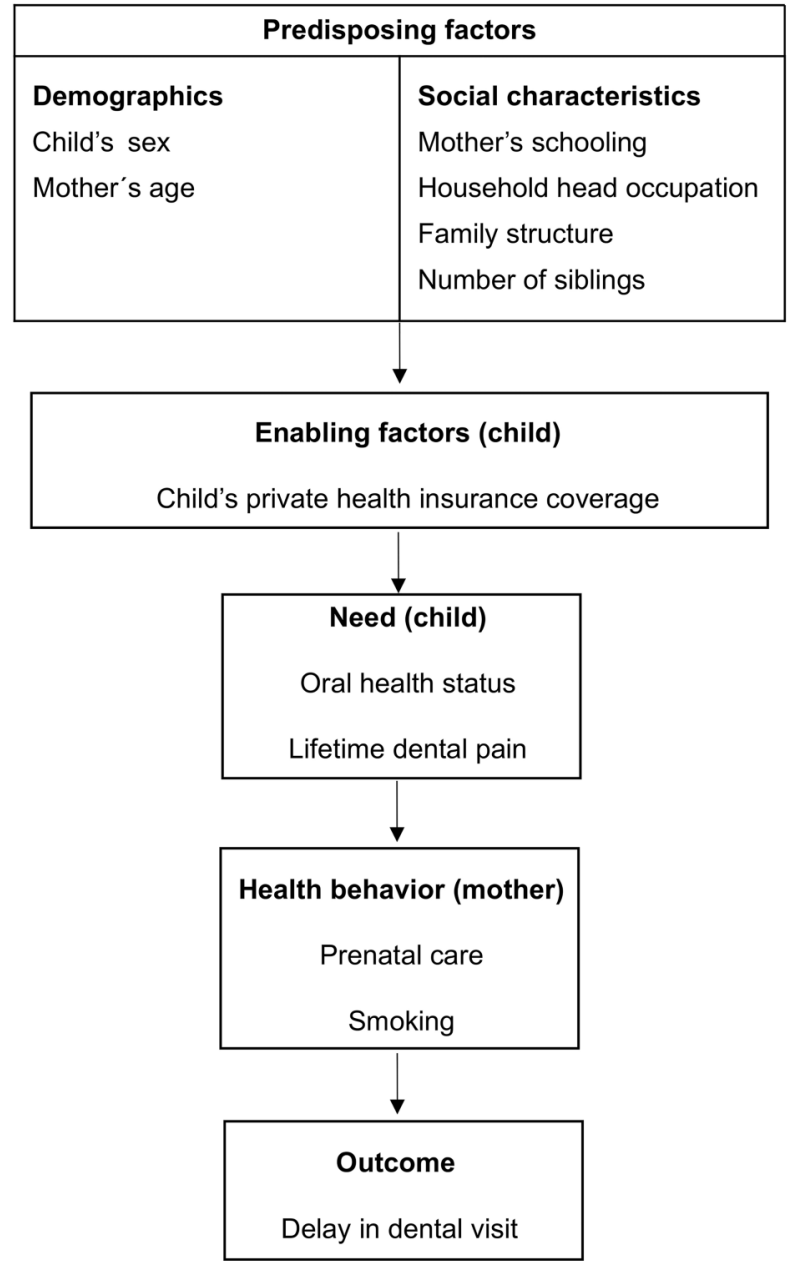

Figure 1. Theoretical model based on the Andersen, Davidson, and Baumeister behavior model of health services utilization (23).

The two questions were combined, discriminating if the child was covered by private health insurance during one or both periods. Stand-alone private dental insurance in Brazil is not common and most of the time is included at no cost as a complement in general health insurances (24).

\section{Statistical analysis}

Sampling design (stratification and weights) was considered in all statistical analyses, which were performed using the SAS (Version 9.3, SAS Institute, USA) and SUDAAN SAS-Callable (Version 11.0, Research Triangle Institute, USA) statistical packages. Descriptive analyses were followed by stratified analysis (for the understanding of covariate association) and modeling for the estimate of prevalence ratios (PR) using Poisson regression with robust estimation of standard errors (25). Modeling was performed using a hierarchical approach (26). The models were constructed according to the Andersen, Davidson, and Baumeister Behavior Model (Figure 1) beginning with 
predisposing factors, followed by enabling, need, and health behavior factors. At each level, we kept variables that were significant at the 0.20 level. We kept not only variables that were significant in the model $(a=0.05)$ but also those that were known to be important for health care utilization in order to permit comparison of the two cohorts.

\section{Results}

The information about age at the first dental visit was missing ("don't know") for $9.7 \%$ of children from RP and $19.7 \%$ of children from SL. Although no association was significant (Table 1), we observed some trends with an increased proportion of missing data among children living only with their fathers for both cohorts and among children from older mothers and those with less than primary education and with higher education in SL.

Figure 2 shows the cumulative distribution of age at the first dental visit. Percentages do not add up to $100 \%$ because of censored data, which represented $37.9 \%$ for SL and $5.1 \%$ for RP. Cumulative percentages were higher for RP than for SL but by the age of six the difference between the two cohorts was smaller (about 10\%), showing that $34.5 \%$ of children in RP and $44.3 \%$ in SL had not seen a dentist by the age of seven.

Table 1. Characteristics of those who did not answer the question about age of the first dental visit in the Ribeirão Preto and São Luís cohorts $(2004 / 2005)$.

\begin{tabular}{|c|c|c|c|c|c|c|c|c|}
\hline & \multicolumn{4}{|c|}{ Ribeirão Preto } & \multicolumn{4}{|c|}{ São Luís } \\
\hline & Total & $\%^{*}$ & $\mathrm{SE}^{\dagger}$ & $\mathrm{P}^{*}$ & Total & $\% *$ & $\mathrm{SE}^{\dagger}$ & $\mathrm{P}^{*}$ \\
\hline \multicolumn{9}{|l|}{ Gender } \\
\hline Male & 402 & 10.7 & 1.7 & 0.3642 & 348 & 18.0 & 2.2 & 0.2954 \\
\hline Female & 388 & 8.6 & 1.5 & & 325 & 21.4 & 2.4 & \\
\hline \multicolumn{9}{|l|}{ Skin Color ${ }^{\S}$} \\
\hline White & 455 & 10.7 & 1.6 & 0.2854 & 158 & 23.6 & 3.5 & 0.1804 \\
\hline Black/dark skin & 335 & 8.3 & 1.6 & & 513 & 18.3 & 1.8 & \\
\hline \multicolumn{9}{|l|}{ Family structure ${ }^{\S}$} \\
\hline Mother \& father & 545 & 9.2 & 1.3 & 0.5960 & 346 & 21.0 & 2.3 & 0.8151 \\
\hline Single mother & 142 & 9.0 & 2.7 & & 165 & 17.3 & 3.1 & \\
\hline Mother \& stepfather & 63 & 9.2 & 4.1 & & 60 & 17.6 & 4.9 & \\
\hline Single father & 20 & 28.8 & 11.2 & & 33 & 23.7 & 7.8 & \\
\hline Without parents & 20 & 12.8 & 8.3 & & 67 & 20.1 & 5.1 & \\
\hline \multicolumn{9}{|l|}{ Oral health ${ }^{\S}$} \\
\hline Excellent & 215 & 11.2 & 2.3 & 0.7385 & 60 & 25.4 & 5.8 & 0.4363 \\
\hline Good & 305 & 9.1 & 1.8 & & 174 & 17.1 & 3.0 & \\
\hline Fair/poor & 270 & 9.2 & 1.9 & & 439 & 19.8 & 2.0 & \\
\hline \multicolumn{9}{|l|}{ Lifetime dental pain ${ }^{\S}$} \\
\hline No & 540 & 10.0 & 1.4 & 0.7154 & 292 & 21.6 & 2.5 & 0.2062 \\
\hline Yes & 245 & 9.2 & 2.0 & & 376 & 17.5 & 2.0 & \\
\hline \multicolumn{9}{|l|}{ Mother's age } \\
\hline$<20$ & 131 & 12.0 & 3.1 & 0.5662 & 199 & 15.8 & 2.7 & 0.0786 \\
\hline $20-35$ & 563 & 8.9 & 1.3 & & 442 & 20.2 & 2.0 & \\
\hline$\geqslant 35$ & 94 & 11.5 & 3.5 & & 32 & 36.8 & 9.1 & \\
\hline \multicolumn{9}{|l|}{ Mother schooling ${ }^{\S}$} \\
\hline$<$ Primary school & 62 & 13.8 & 4.7 & 0.8538 & 42 & 28.5 & 7.3 & 0.2887 \\
\hline Primary school & 283 & 10.2 & 1.9 & & 181 & 15.5 & 2.8 & \\
\hline Middle school & 164 & 8.3 & 2.4 & & 154 & 20.2 & 3.4 & \\
\hline High school & 194 & 8.8 & 2.3 & & 266 & 18.2 & 2.5 & \\
\hline Bachelor degree + & 79 & 8.7 & 3.2 & & 12 & 41.4 & 15.6 & \\
\hline \multicolumn{9}{|l|}{ Prenatal care visits } \\
\hline $0-3$ & 215 & 11.2 & 2.3 & 0.7385 & 60 & 25.4 & 5.8 & 0.4363 \\
\hline $4-5$ & 305 & 9.1 & 1.8 & & 174 & 17.1 & 3.0 & \\
\hline$\geqslant 6$ & 270 & 9.2 & 1.9 & & 439 & 19.8 & 2.0 & \\
\hline
\end{tabular}

*Weighted percentage; ‘'standard error; ${ }^{\dagger} \mathrm{P}$ value for Wald test; ${ }^{\S}$ information from the follow-up. 


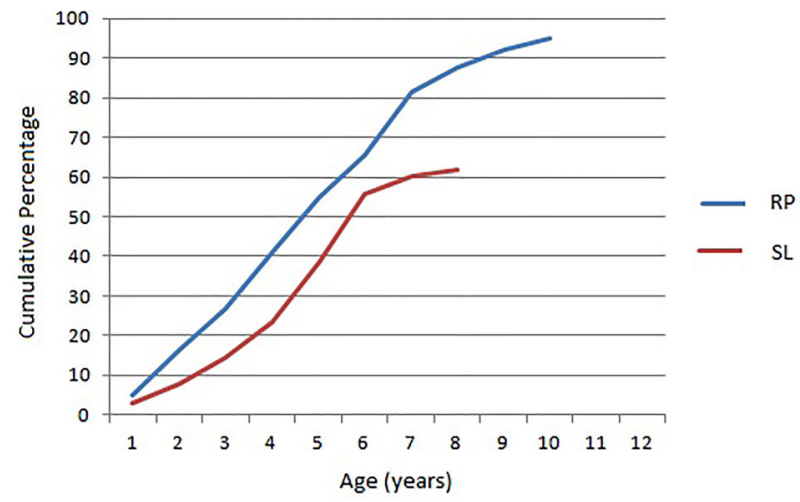

Figure 2. Cumulative distribution of age at first dental visit in the Ribeirão Preto (RP) and São Luís (SL) cohorts (2004/2005). Lines do not add up to $100 \%$ because of censored data (those who had not seen a dentist by the time of follow-up).

Bivariate analysis (Table 2) showed that, for both cohorts, the percentage of children not visiting a dentist before the age of seven was significantly higher among those with more siblings, without private health insurance, and lower levels of mother's schooling. For some variables, statistically significant associations were observed only for RP such as being non-white, having poor oral health, and fewer prenatal care visits. Lifetime experience of dental pain was positively associated with not going to the dentist before the age of seven for RP, while it was negatively associated for SL.

Table 3 shows results for each level of the Andersen, Davidson, and Baumeister model (intermediate model) while the final adjusted model is presented in Table 4. Predisposing and enabling factors were very similar in both intermediate (Table 3) and final (Table 4) models. Among predisposing factors, only mother's schooling was statistically associated with a child not going to the dentist before the age of seven for both cohorts. The pattern of association of family structure was similar for both cohorts but only significant for RP. However, for both cohorts, the prevalence ratios for single-father families and families with no biological parents were higher than for nuclear families. The number of siblings was only significant for SL. Having private health insurance, an enabling factor, was negatively associated with dental visit delay for both cities. Among need level, life-time dental pain was statistically associated with dental visit delay for both cities in the intermediate model (Table 3 ) but remained significant only for SL in the final model (Table 4). The significance of oral health status that was only observed for RP in the intermediate model disappeared in the final model. Among health behavior-related variables, number of prenatal care visits was statistically significant for both cohorts, but only remained significant after adjustment for RP. Smoking that was significant only for RP in the intermediate model lost its significance after adjustment.

\section{Discussion}

In spite of the consensus that children should visit a dentist at the latest by the time of first tooth eruption (1), our study shows that less than $5 \%$ of children were taken to a dentist before the age of two in both cohorts. By the age of six, about 34.5 and $44.3 \%$ of children in RP and SL, respectively, had not yet visited a dentist and this proportion was still impressively high by the age of eight $(\mathrm{RP}=12.3 \%$ and $\mathrm{SL}=38.3 \%$ ). It should be highlighted that this scenario occurred in $2004 / 2005$, i.e., before implementation of the NOHP (11).

Brazil is a country with a health system that is a publicprivate mixture with free dental services for all individuals through the public Unified Health System (SUS in the Portuguese acronym) (27). However, created in 1988 and with a major expansion after 2003, SUS is still considered to be under development in an attempt to equitably cover the population in collaboration with the private sector (27). A major development of oral health services was observed mostly after 2004 with the NOHP. Among other actions, this policy created a financial incentive for the inclusion of oral health teams in the Family Health Strategy in an attempt to reorganize the Primary Health Care model and to reduce oral health inequalities in Brazil (11). Furthermore, the NOHP promoted the regulation of the Dental Specialty Centers, which was important by increasing access to dental visits for very young children (11). Actually, since our data were collected before the implementation of NOHP in Brazil, it is valid to hypothesize that the current situation should be better, especially in RP, as the provision of oral health services has been considerably widespread within the Family Health Strategy. From 2007 to 2019, there was an expansion of $129 \%$ in the proportion of the Brazilian population with access to oral health services in Primary Health Care. However, there are important inequalities among regions and cities in Brazil. In RP, this increase was more than 10 times (from $3.08 \%$ in 2007 to $32.57 \%$ in $2019)$, while the coverage remained the same $(21 \%)$ in SL (28).

Unfortunately, the availability of dental care in the public setting is still a concern, (29) especially for younger children (30). As a result, in spite of a $10 \%$ improvement in dental care access compared to the previous decade, two national surveys conducted in 2008 (15) and 2010 (17), respectively, showed that $67.2 \%$ of children up to 6 years old and $46.8 \%$ of children at 5 years of age had never visited a dentist. Since dental services are also provided by the private sector, it is important to mention the extremely high dentist-to-population ratio in Brazil (1:832) and especially in RP (1:286) and SL (1:568) (31).

When compared to the national average of available information from 2008 (67.2\%) (14), our study showed lower percentages of children who had not visited a dentist by the age of seven (35\% in RP and $44.3 \%$ in SL). By the age of five, the percentages (RP: $45.3 \%$ and 
Table 2. Bivariate analysis results for children who had not seen a dentist before the age of 7 in the Ribeirão Preto and São Luís cohorts.

\begin{tabular}{|c|c|c|c|c|c|c|}
\hline & \multicolumn{3}{|c|}{ Ribeirão Preto } & \multicolumn{3}{|c|}{ São Luís } \\
\hline & $\mathrm{n}$ & $\%^{*}(\mathrm{SE})^{\dagger}$ & $\mathrm{P}^{\ddagger}$ & $\mathrm{n}$ & $\%(\mathrm{SE})^{\dagger}$ & $\mathrm{P}^{ \pm}$ \\
\hline \multicolumn{7}{|l|}{ Mother's schooling } \\
\hline$<$ Primary school & 76 & $63.1(5.9)$ & & 54 & $45.5(6.9)$ & \\
\hline Primary school & 251 & $41.9(3.3)$ & $<0.001$ & 191 & $46.2(3.7)$ & $<0.001$ \\
\hline Middle school & 148 & $25.2(3.8)$ & & 153 & $35.7(4.0)$ & \\
\hline Secondary school & 93 & $15.2(4.0)$ & & 132 & $15.1(3.1)$ & \\
\hline Bachelor's degree + & 83 & $7.7(3.2)$ & & 13 & $28.0(12.1)$ & \\
\hline \multicolumn{7}{|l|}{ Household occupation } \\
\hline Non-manual worker & 138 & $10.8(2.8)$ & $<0.001$ & 71 & $24.1(5.3)$ & 0.0286 \\
\hline Skilled manual & 265 & $35.9(3.1)$ & & 153 & $31.2(3.8)$ & \\
\hline Unskilled manual & 309 & $42.9(3.0)$ & & 316 & $39.1(2.8)$ & \\
\hline \multicolumn{7}{|l|}{ Family structure } \\
\hline Mother \& father & 495 & $32.1(2.2)$ & & 274 & $33.8(2.9)$ & \\
\hline Single mother & 131 & $32.4(4.3)$ & 0.0769 & 137 & $33.4(4.1)$ & 0.8684 \\
\hline Mother \& stepfather & 58 & $56.6(7.0)$ & & 50 & $37.1(6.9)$ & \\
\hline Single father & 14 & $60.4(14.1)$ & & 26 & $40.7(6.7)$ & \\
\hline Without parents & 17 & $61.2(12.3)$ & & 54 & $38.7(9.8)$ & \\
\hline \multicolumn{7}{|l|}{ Number of siblings } \\
\hline 0 & 125 & $29.9(4.4)$ & & 140 & $30.3(4.0)$ & \\
\hline 1 & 278 & $28.1(2.8)$ & 0.0075 & 212 & $28.5(3.2)$ & 0.0013 \\
\hline 2 & 193 & $36.2(3.7)$ & & 125 & $41.0(4.5)$ & \\
\hline 3 & 63 & $46.1(6.7)$ & & 37 & $48.5(8.4)$ & \\
\hline $4+$ & 56 & $51.4(7.0)$ & & 29 & $65.4(8.9)$ & \\
\hline \multicolumn{7}{|l|}{ Skin color } \\
\hline White & 388 & $27.6(2.4)$ & 0.0004 & 120 & $33.9(4.4)$ & 0.0994 \\
\hline Non-white & 324 & $41.2(2.9)$ & & 421 & $35.5(2.4)$ & \\
\hline \multicolumn{7}{|l|}{ Gender } \\
\hline Female & 360 & $33.8(2.7)$ & 0.8365 & 287 & $39.3(4.4)$ & 0.0388 \\
\hline Male & 355 & $34.7(2.7)$ & & 256 & $30.6(3.0)$ & \\
\hline \multicolumn{7}{|l|}{ Health insurance } \\
\hline Never & 234 & $14.3(2.5)$ & $<0.001$ & 33 & $10.2(5.6)$ & $<0.0001$ \\
\hline One period & 198 & $39.4(3.6)$ & & 58 & $14.1(4.6)$ & \\
\hline Continuous & 282 & $46.2(3.1)$ & & 275 & $39.4(2.3)$ & \\
\hline \multicolumn{7}{|l|}{ Oral Health } \\
\hline Excellent/very good & 191 & $26.4(3.4)$ & & 45 & $22.4(6.2)$ & \\
\hline Good & 279 & $31.1(2.9)$ & 0.0014 & 145 & $33.9(4.0)$ & 0.0988 \\
\hline Fair/poor & 245 & $43.2(3.4)$ & & 353 & $37.4(2.6)$ & \\
\hline \multicolumn{7}{|l|}{ Life-time dental pain } \\
\hline No & 488 & $29.4(2.2)$ & 0.0007 & 354 & $40.5(3.3)$ & 0.0281 \\
\hline Yes & 222 & $43.6(3.5)$ & & 309 & $31.1(2.7)$ & \\
\hline \multicolumn{7}{|l|}{ Prenatal care visits $\$$} \\
\hline $6+$ & 508 & $29.5(2.1)$ & 0.0002 & 273 & $31.1(2.9)$ & 0.0697 \\
\hline $4-5$ & 98 & $41.3(5.4)$ & & 141 & $35.9(4.1)$ & \\
\hline $0-3$ & 42 & $66.6(7.9)$ & & 117 & $43.8(4.7)$ & \\
\hline \multicolumn{7}{|l|}{ Mother's smoking } \\
\hline No & 581 & $31.8(2.1)$ & 0.0122 & 508 & $35.3(2.2)$ & 0.0311 \\
\hline Yes & 134 & $44.7(4.6)$ & & 35 & $33.8(8.3)$ & \\
\hline
\end{tabular}

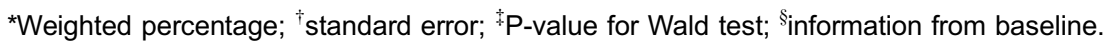


Table 3. Multivariable analysis for each level of predisposing, enabling, need, and health behavior factors. Results showing prevalence ratios (PR) for covariates for children who did not visit a dentist before the age of 7 in the Ribeirão Preto and São Luís cohorts (2004/ 2005).

\begin{tabular}{|c|c|c|c|c|c|c|}
\hline \multirow[t]{2}{*}{ Factors } & \multicolumn{3}{|c|}{ Ribeirão Preto } & \multicolumn{3}{|c|}{ São Luís } \\
\hline & PR & $95 \% \mathrm{Cl}^{\dagger}$ & $\mathrm{P}^{+}$ & PR & $95 \% \mathrm{Cl}^{\dagger}$ & $\mathrm{P}^{*}$ \\
\hline \multicolumn{7}{|l|}{ Predisposing factors } \\
\hline \multicolumn{7}{|l|}{ Mother's schooling } \\
\hline$<$ Primary school & 1.00 & & & 1.00 & & 0.0019 \\
\hline Primary school & 0.67 & $0.62-1.00$ & $<0.0001$ & 1.03 & $0.73-1.47$ & \\
\hline Middle school & 0.43 & $0.36-0.82$ & & 0.92 & $0.61-1.37$ & \\
\hline Secondary school & 0.29 & $0.23-0.88$ & & 0.39 & $0.23-0.68$ & \\
\hline Bachelor's degree + & 0.20 & $0.35-0.85$ & & 0.71 & $0.24-2.10$ & \\
\hline \multicolumn{7}{|l|}{ Household occupation } \\
\hline Non-manual worker & 1.00 & & 0.0894 & 1.00 & & 0.4020 \\
\hline Skilled manual & 1.79 & $1.00-3.21$ & & 1.24 & $0.76-2.03$ & \\
\hline Unskilled manual & 1.92 & $1.07-3.44$ & & 1.34 & $0.86-2.10$ & \\
\hline \multicolumn{7}{|l|}{ Family structure } \\
\hline Mother \& father & 1.00 & & 0.0079 & 1.00 & & 0.6501 \\
\hline Single mother & 0.96 & $0.71-1.23$ & & 1.01 & $0.75-1.38$ & \\
\hline Mother \& stepfather & 1.22 & $0.85-1.77$ & & 1.04 & $0.71-1.53$ & \\
\hline Single father & 1.47 & $0.86-2.51$ & & 1.38 & $0.90-2.12$ & \\
\hline Without parents & 2.16 & $1.37-3.41$ & & 1.11 & $0.66-1.86$ & \\
\hline \multicolumn{7}{|l|}{ Number of siblings } \\
\hline 0 & 1.00 & & 0.5965 & 1.00 & & 0.0057 \\
\hline 1 & 1.24 & $0.88-1.75$ & & 0.93 & $0.64-1.34$ & \\
\hline 2 & 1.25 & $0.88-1.78$ & & 1.31 & $0.90-1.94$ & \\
\hline 3 & 1.44 & $0.91-2.27$ & & 1.39 & $0.87-2.22$ & \\
\hline $4+$ & 1.22 & $0.79-1.87$ & & 1.80 & $1.19-2.73$ & \\
\hline \multicolumn{7}{|l|}{ Gender } \\
\hline Female & 1.00 & & 0.5894 & 1.00 & & 0.0846 \\
\hline Male & 1.06 & $0.85-1.33$ & & 0.81 & $0.64-1.03$ & \\
\hline \multicolumn{7}{|l|}{ Skin color } \\
\hline White & 1.00 & & 0.2842 & 1.00 & & 0.8633 \\
\hline Non-white & 1.14 & $0.89-1.33$ & & 0.98 & $0.74-1.29$ & \\
\hline \multicolumn{7}{|l|}{ Enabling factor } \\
\hline \multicolumn{7}{|l|}{ Health insurance } \\
\hline Never & 1.00 & & $<0.0001$ & 1.00 & & $<0.0001$ \\
\hline For some period & 0.85 & $0.68-1.07$ & & 0.36 & $0.19-0.69$ & \\
\hline Continuously & 0.52 & $0.21-0.45$ & & 0.26 & $0.09-0.76$ & \\
\hline \multicolumn{7}{|l|}{ Need factors } \\
\hline \multicolumn{7}{|l|}{ Oral Health } \\
\hline Excellent/very good & 0.88 & $0.64-1.22$ & 0.0025 & 0.67 & $0.37-1.22$ & 0.2000 \\
\hline Good & 1.00 & & & 1.00 & & \\
\hline Fair/poor & 1.21 & $1.02-1.87$ & & 1.33 & $1.00-1.78$ & \\
\hline \multicolumn{7}{|l|}{ Life-time dental pain } \\
\hline No & 1.00 & & 0.0162 & 1.00 & & 0.0013 \\
\hline Yes & 1.37 & $1.03-1.69$ & & 0.67 & $0.52-0.85$ & \\
\hline \multicolumn{7}{|l|}{ Behavior factors } \\
\hline \multicolumn{7}{|l|}{ Prenatal care visits ${ }^{\S}$} \\
\hline $6+$ & 1.00 & & $<0.0001$ & 1.00 & & 0.0487 \\
\hline $4-5$ & 1.38 & $1.03-1.55$ & & 1.16 & $0.87-1.54$ & \\
\hline $0-3$ & 2.18 & $1.66-2.87$ & & 1.42 & $1.09-1.87$ & \\
\hline \multicolumn{7}{|l|}{ Mother's smoking } \\
\hline No & 1.00 & & 0.0430 & 1.00 & & 0.4855 \\
\hline Yes & 1.31 & $1.01-1.69$ & & 0.82 & $0.46-1.44$ & \\
\hline
\end{tabular}

${ }^{\dagger} 95 \% \mathrm{Cl}$ : 95\% confidence interval; ${ }^{\dagger} \mathrm{P}$-value for Wald chi-squared; ${ }^{\circledR}$ information collected at birth. 
Table 4. Final multivariable analysis results showing prevalence ratios $(P R)$ for covariates for children who did not visit a dentist before the age of 7 in the Ribeirão Preto and São Luís cohorts (2004/2005).

\begin{tabular}{|c|c|c|c|c|c|c|}
\hline \multirow[t]{2}{*}{ Factors } & \multicolumn{3}{|c|}{ Ribeirão Preto } & \multicolumn{3}{|c|}{ São Luís } \\
\hline & PR & $95 \% \mathrm{Cl}^{\dagger}$ & $\mathrm{P}^{*}$ & PR & $95 \% \mathrm{Cl}^{\dagger}$ & $\mathrm{P}^{\star}$ \\
\hline \multicolumn{7}{|l|}{ Predisposing factors } \\
\hline \multicolumn{7}{|l|}{ Mother's schooling ${ }^{\S}$} \\
\hline$<$ Primary school & 1.00 & & & 1.00 & & 0.0264 \\
\hline Primary school & 0.82 & $0.62-1.00$ & 0.0135 & 1.09 & $0.74-1.63$ & \\
\hline Middle school & 0.54 & $0.36-0.82$ & & 0.99 & $0.64-1.52$ & \\
\hline Secondary school & 0.45 & $0.23-0.88$ & & 0.50 & $0.28-0.89$ & \\
\hline Bachelor's degree + & 0.35 & $0.35-0.85$ & & 1.07 & $0.36-3.16$ & \\
\hline \multicolumn{7}{|l|}{ Household occupation $\$$} \\
\hline Non-manual worker & 1.00 & & 0.2763 & 1.00 & & 0.7849 \\
\hline Skilled manual & 1.61 & $0.90-2.89$ & & 1.11 & $0.68-1.82$ & \\
\hline Unskilled manual & 1.52 & $0.85-2.72$ & & 1.16 & $0.75-1.81$ & \\
\hline \multicolumn{7}{|l|}{ Family structure ${ }^{\S}$} \\
\hline Mother \& father & 1.00 & & 0.0004 & 1.00 & & 0.7401 \\
\hline Single mother & 0.90 & $0.66-1.24$ & & 1.06 & $0.64-1.44$ & \\
\hline Mother \& stepfather & 1.01 & $0.66-1.53$ & & 0.96 & $0.86-2.07$ & \\
\hline Single father & 1.77 & $1.12-2.79$ & & 1.33 & $0.64-1.98$ & \\
\hline Without parents & 2.34 & $1.52-3.60$ & & 1.12 & $0.86-2.07$ & \\
\hline \multicolumn{7}{|l|}{ Number of siblings } \\
\hline 0 & 1.00 & & 0.7189 & 1.00 & & 0.0227 \\
\hline 1 & 1.24 & $0.86-1.78$ & & 0.93 & $0.65-1.33$ & \\
\hline 2 & 1.22 & $0.85-1.77$ & & 1.28 & $0.87-1.88$ & \\
\hline 3 & 1.20 & $0.71-2.04$ & & 1.42 & $0.89-2.07$ & \\
\hline $4+$ & 1.05 & $0.67-1.64$ & & 1.65 & $1.09-2.51$ & \\
\hline \multicolumn{7}{|l|}{ Gender } \\
\hline Female & 1.00 & & 0.2935 & 1.00 & & 0.0886 \\
\hline Male & 1.19 & $0.89-1.45$ & & 0.81 & $0.64-1.03$ & \\
\hline \multicolumn{7}{|l|}{ Skin color } \\
\hline White & 1.0 & & 0.2582 & 1.00 & & 0.9846 \\
\hline Non-white & 1.14 & $0.89-1.47$ & & 1.00 & $0.75-1.33$ & \\
\hline \multicolumn{7}{|l|}{ Enabling factor } \\
\hline \multicolumn{7}{|l|}{ Health insurance } \\
\hline Never & 1.00 & & 0.0391 & 1.00 & & 0.0227 \\
\hline For some period & 1.00 & $0.77-1.31$ & & 0.43 & $0.22-0.85$ & \\
\hline Continuously & 0.52 & $0.32-0.84$ & & 0.34 & $0.12-0.98$ & \\
\hline \multicolumn{7}{|l|}{ Need factors } \\
\hline \multicolumn{7}{|l|}{ Oral health } \\
\hline Excellent/very good & 1.34 & $0.96-1.86$ & 0.1817 & 0.75 & $0.42-1.32$ & 0.2909 \\
\hline Good & 1.00 & & & 1.00 & & \\
\hline Fair/poor & 1.21 & $0.91-1.60$ & & 1.14 & $0.85-1.52$ & \\
\hline \multicolumn{7}{|l|}{ Life-time dental pain } \\
\hline No & 1.00 & & 0.3761 & 1.00 & & 0.0014 \\
\hline Yes & 1.13 & $0.86-1.45$ & & 0.66 & $0.52-0.85$ & \\
\hline \multicolumn{7}{|l|}{ Behavior factors } \\
\hline \multicolumn{7}{|l|}{ Prenatal care visits ${ }^{\S}$} \\
\hline $6+$ & 1.00 & & 0.0405 & 1.00 & & 0.5391 \\
\hline $4-5$ & 0.91 & $0.65-1.27$ & & 0.90 & $0.68-1.19$ & \\
\hline $0-3$ & 1.45 & $1.05-2.00$ & & 1.07 & $0.81-1.41$ & \\
\hline \multicolumn{7}{|l|}{ Mother's smoking } \\
\hline No & 1.00 & & 0.0528 & 1.00 & & 0.9796 \\
\hline Yes & 1.30 & $1.00-1.69$ & & 0.99 & $0.55-1.78$ & \\
\hline
\end{tabular}

${ }^{\dagger} 95 \% \mathrm{Cl}$ : 95\% confidence interval; ${ }^{\dagger} \mathrm{P}$-value for Wald chi-squared; ${ }^{\$}$ information collected at birth. 
SL: $54.9 \%$ ) were also lower than the $63 \%$ reported in the Pelotas' population cohort study conducted in the south of Brazil (16). However, our results for 5-year-olds were closer to those of the 2010 National Oral Health Survey $(46.8 \%)$ (15). The lower percentages observed in our study probably reflect, at least in part, differences in socioeconomic status among our cohorts, the Pelotas' study, and the national average. However, even though $\mathrm{RP}$ has one of the highest MHDI in the country, SL and Pelotas have a closely similar low $\mathrm{MHDI}$, and the dentistto-population ratio in Pelotas $(1: 471)$ is even higher than in SL (1:568) (31). Therefore, the reasons for the differences between SL and Pelotas need to be further investigated.

Although the availability of health services is essential for utilization, some individuals are unaware of the benefit or unable/unwilling to use the services even when they are provided free of charge (32). Delay in dental visits can also be observed in well-established universal health systems such as that of the United Kingdom, where the rate of dental visits by the age of two has been stable around $30 \%$. A low percentage of dental visits by the age of two $(44.5 \%)$ was also reported in the evaluation of the Free First Visit program in Canada (33) which, however, did not consider the non-take up of the program (32). More recently, timing of first dental visit has only been reported in studies from convenience samples such as one study in India, where $57 \%$ of children seen at the pediatric dentistry department of a tertiary-care hospital in Puducherry had their first dental visit by the age of 6-9 years (34). Another study in Poland showed that $92.2 \%$ of the children who went for the first time to four private dental clinics had their first visit before 7 years of age (35). However, due to the sampling design, those results are subject to selection bias, overestimating prevalence.

In our study, even among the most highly educated mothers, only $39.9 \%$ in RP and $9.73 \%$ in SL had taken their children to a dentist by the age of two. It would be expected that highly educated mothers would be able to afford dental services or have the means to access those that are free of charge. A possible explanation is that these mothers consciously postpone the first dental visit because of a lower prevalence of dental caries among their children. Moreover, we should take into account beliefs and low literacy regarding the importance of children's oral health (36).

Comparison of the cumulative percentage of children who had not visited a dentist showed that the difference between the two cities was smaller around the age of six (a $10 \%$ difference). This decrease in the difference might be related to the reasons for taking children to their first dental visit, which might be the eruption of the first permanent molars and the enrollment in elementary school, both taking place around the age of six. However, the SL cohort showed lower cumulative levels for children younger than six and especially for children older than seven. Although we do not have information about the availability of dental services at public community centers for RP children, the dentist-to-population ratio for the RP population is considerably higher $(1: 286)$ than that for SL (1:568), a fact that may explain in part these differences (31).

Multivariable analysis revealed that mother's schooling and private health insurance were the only variables associated with not visiting a dentist before the age of seven for both cohorts. Although the association of health insurance and health service utilization is well known, we should be careful with our interpretation. As stated before, private dental insurance is not common in Brazil and most of it is offered in combination with general health insurance (24). Therefore, in this study, the association with health insurance is probably more related to the purchasing power of the family than specifically to the access to dental services. Moreover, since the variable we used in this study described the continuity of health insurance coverage throughout the child's life, this variable probably also measures the economic stability of the family, which would more likely result in health-seeking behavior.

The contrasts in the final models for RP and SL probably reflect differences in socioeconomic structure, as well as in the prevalence and distribution of dental caries among the cohorts. Although we did not have information on dental caries from dental examinations, our study showed that $65.3 \%$ of mothers reported poor oral health for their children in SL compared to $34.7 \%$ in RP. Moreover, although poor oral health was associated with mother's schooling in both SL and RP, it was more widespread in SL than in RP. In the SL cohort, poor oral health of the child was reported by $71.6 \%$ of mothers of lower educational level compared to $61.5 \%$ of mothers with the highest educational level. In contrast, these percentages were respectively 53.6 and $12.0 \%$ in RP. Moreover, lifetime dental pain due to dental caries was significantly higher among SL children $(56.4 \%)$ already at $7 / 8$ years of age compared to RP children at $11 / 12$ years of age (32.4\%). Taking this evidence into consideration, we may infer that the negative association of lifetime dental pain with not visiting a dentist before the age of seven in SL was probably a result of health care-seeking behavior. It is important to point out that this association found in SL was not a result of overadjustment by oral health perception.

Although family structure is an important determinant of children's health care utilization (37), there are only few studies addressing its association with dental services (37-39). In our study, we detected an increased prevalence of children who had not visited a dentist before the age of seven among those living in single-father families and in families with no biological parents compared with those living in nuclear families. We found only one study in which single-father families were studied and were associated with lower rates of child health service utilization in general, except for dental service utilization, which was explained by socioeconomic variables (39). In contrast to the literature reporting lower health service utilization among children from single-mother families, we could not observe this trend in either cohort. 
Two health behaviors related to mothers, i.e., low number of prenatal care visits and smoking habit, were associated with a child not visiting a dentist before the age of seven only in RP. The lack of association with mother smoking habit in SL might be explained by the well-known low prevalence of smoking among women from SL (40). Using the same reasoning, a very high prevalence of a type of exposure might also turn into a weak indicator of an event, as might have been the case for the high percentage $(50 \%)$ of low number of prenatal visits in SL. Similarly, a large number of siblings was an important factor associated only in the SL cohort. The lack of significance for number of siblings in RP might be explained by the strong association between the outcome of interest and mother's educational level which, when added to the model, removed the significance of number of siblings as a predictor.

Among the limitations of this study is the possibility of recall bias related to the outcome, which was reported at follow-up. However, the first dental visit is frequently a special event in a child's life, requiring mothers to make an appointment either for preventive reasons or because of pain or trauma, which might limit recall bias. The lack of information about the motives of the first dental visit may be claimed as another potential limitation. However, as discussed before, the reasons for taking a child to a dentist for the first time (treatment vs prevention) may compete with each other, and our major objective was to characterize those children who had not seen a dentist before the age of seven, which would be considered unacceptable. It is important also to point out that the data used in this study were collected in 2004/2005, before the NOHP was implemented. Probably, there has been some improvement in access to oral health services; however, no new

\section{References}

1. American Academy of Pediatric Dentistry. Guideline on Periodicity of Examination, Preventive Dental Services, Anticipatory Guidance/Counseling, and Oral Treatment for Infants, Children, and Adolescents. < http://www.aapd.org/ media/Policies_Guidelines/G_Periodicity.pdf $>$.

2. Bhaskar V, McGraw KA, Divaris K. The importance of preventive dental visits from a young age: systematic review and current perspective. Clin Cosmet Investig Dent 2014; 6: 21-27, doi: 10.2147/CCIDE.S41499.

3. Plutzer K, Keyser MJ. Influence of an intervention to prevent early childhood caries initiated before birth on children's use of dental services up to 7 years of age. Open Dent J 2014; 8: 104-108, doi: 10.2174/1874210601408010104.

4. Savage MF, Lee JY, Kotch JB, Vann WF Jr. Early preventive dental visits: effects of subsequent utilization and costs. Pediatrics 2004; 114: e418-e423, doi: 10.1542/peds.2003-0469-F.

5. Beil H, Rozier G, Preisser JS, Stearns SC, Lee JY. Effect of early preventive dental visits on subsequent dental treatment and expenditures. Med Care 2012; 50: 749-756, doi: 10.1097/MLR.0b013e3182551713.

6. Beil H, Rozier G, Preisser JS, Stearns SC, Lee JY. Effects of early dental office visits on dental caries experience. Am J population-based study reporting delay in dental visits for Brazilian children has been published since 2013. The present data are therefore important for future comparisons and analysis of the long-term effect of the NOHP.

In spite of its limitations, this study had several strengths. It is the first report of timing of the first dental visit in two population cohorts using the same research protocol, which included several important associated factors collected at birth and at follow-up. This enabled us to study the same outcome with similar availability of dental care in a heterogeneous population with a lower prevalence of dental caries polarized among the poorest (RP) compared to a more homogeneous population with high prevalence and widespread distribution of dental caries (SL).

In conclusion, this study revealed that, in 2004-2005, a very low percentage of children of both cohorts were taken to their first dental visit within the recommended period of 12 months of age. Moreover, delay in dental visits after the age of six was very high even among children of more educated mothers. Further studies are necessary to analyze what has changed in access to the first dental visit after the NOHP in Brazil and to understand what underlies the decision of Brazilian mothers to take their children to the dentist for the first time.

\section{Acknowledgments}

This study was funded by Fundação de Amparo à Pesquisa do Estado de São Paulo, Brazil (FAPESP, Grant \#00/09508-7) and Coordenação de Aperfeiçoamento de Pessoal de Nível Superior, Brazil (CAPES, Finance Code 001; Doctoral fellowship for A.L.F.H. Soares).

Public Health 2014; 104: 1979-1985, doi: 10.2105/AJPH. 2013.301325.

7. Ismail Al, Sohn W. The impact of universal access to dental care on disparities in caries experience in children. $J \mathrm{Am}$ Dent Assoc 2001; 132: 295-303, doi: 10.14219/jada. archive.2001.0172.

8. Murray JJ, Vernazza CR, Homes RD. Forty years of national surveys: an overview of children's dental health from 19732013. Br Dent J 2015; 219: 281-285, doi: 10.1038/sj.bdj. 2015.723.

9. Vargas CM, Ronzio CR. Relationship between children's dental needs and dental care utilization: United States, 1988-1994. Am J Public Health 2002; 92: 1816-1821, doi: 10.2105/AJPH.92.11.1816.

10. Pucca GA Jr, Gabriel M, de Araujo ME, de Almeida FCS. Ten years of a National Oral Health Policy in Brazil: innovation, boldness, and numerous challenges. J Dent Res 2015; 94: 1333-1337, doi: 10.1177/0022034515599979.

11. Herkrath FJ, Vettore MV, Werneck GL. Contextual and individual factors associated with dental services utilisation by Brazilian adults: a multilevel analysis. PLoS One 2018; 13: e0192771, doi: 10.1371/journal.pone.0192771. 
12. Queiroz RCS, Ribeiro AGA, Tonello AS, Pinheiro ACM, Aquino $\mathrm{J} \mathrm{Jr}$, Rocha TAH, et al. Is there a fair distribution of the structure of dental services in the capitals of the Brazilian Federative Units? Int J Equity Health 2019; 18: 5, doi: 10.1186/s12939-018-0899-5.

13. Peres KG, Peres MA, Boing AF, Bertoldi AD, Bastos JL, Barros AJ. Reduction of social inequalities in utilization of dental care in Brazil from 1998 to 2008 [in Portuguese]. Rev Saúde Publica 2012; 46: 250-258.

14. Souza JGS, Sampaio AA, Costa Oliveira BE, Jones KM, Martins AMEBL. Int J Paediatr Dent 2018; 28: 400-409, doi: 10.1111/ipd.12368.

15. Camargo MB, Barrros AJ, Frazão, Matijasevich A, Santos IS, Peres $\mathrm{Ma}$, et al. Predictors of dental visits for routine checkups and for the resolution of problems among preschool children [in Portuguese]. Rev Saúde Publica 2012; 46: 87-97.

16. Bettiol H, Barbieri MA, Gomes UA, Andréa M, Goldani MZ, Ribeiro ERO. Perinatal health: methodology and some characteristics of the population studied [in Portuguese]. Rev Saúde Publica 1998; 32: 18-28, doi: 10.1590/s003489101998000100003.

17. Silva AA, Coimbra LC, Silva RA, Alves MT, Lamy-Filho F, Lamy ZC, et al. Perinatal health and mother-child health care in the municipality of São Luís, Maranhão State, Brazil. Cad Saúde Publica 2001; 17: 1413-1423, doi: 10.1590/ S0102-311X2001000600012.

18. PNUD. Atlas de Desenvolvimento Humano no Brasil. Ranking IDHM Municípios 2000. http://www.pnud.org.br/ atlas/ranking/Ranking-IDHM-Municipios-2000.aspx.

19. DATASUS: População Residente - São Paulo. População Residente segundo Município. Município: Ribeirão Preto. Período: 2007. Brasília: Ministério da Saúde; 2007. <http:// tabnet.datasus.gov.br/cgi/tabcgi.exe?ibge/cnv/popsp.htm > .

20. DATASUS. População Residente - Maranhão. População Residente segundo Município. Município: São Luís. Período: 2007. Brasília: Ministério da Saúde; 2007. <http://tabnet. datasus.gov.br/cgi/tabcgi.exe?ibge/cnv/popma.htm > .

21. Silva AA, Barbieri MA, Cardoso VC, Batista RF, Simões VM, Vianna EO, et al. Prevalence of non-communicable diseases in Brazilian children: follow-up at school age of two Brazilian birth cohorts of the 1990's. BMC Public Health 2011; 11: 486, doi: 10.1186/1471-2458-11-486.

22. Wright JT, Crall JJ, Fontana M, Gillette EJ, Nový BB, Dhar V, et al. Evidence-based clinical practice guideline for the use of pit-and-fissure sealants: A report of the American Dental Association and the American Academy of Pediatric Dentistry. J Am Dent Assoc. 2016 Aug;147(8):672-682.e12, doi: 10.1016/j.adaj.2016.06.001.

23. Andersen RM, Davidson PL, Baumeister SE. Improving access to care in America. In: Kominsk GF (Editor), Changing the U.S. health care system: Key issues in health services policy and management. 4th ed. Hoboken: John Wiley and Sons. p 33.

24. Pietrobon L, da Silva CM, Batista LR, Caetano JC. Health care plans: interfaces between the public and private system in dental sector [in Portuguese]. Cien Saude Colet 2008; 13: 1589-1599, doi: 10.1590/S1413-81232008000500023.

25. Barros AJ, Hirakata VN. Alternatives for logistic regression in cross-sectional studies: an empirical comparison of models that directly estimate prevalence ratios. BMC Med Res Methodol 2003; 3: 21, doi: 10.1186/1471-2288-3-21.
26. Victora GC, Huttly SR, Fuchs SC, Olinto MT. The role of conceptual framework in epidemiological analysis: hierarchical approach. Int J Epidemiol 1997; 26: 224-227, doi: 10.1093/ije/26.1.224.

27. Paim J, Travassos C, Almeida C, Bahia C, Macinko J. The Brazilian health system: history, advances and challenges. Lancet 2011; 377: 1778-1797, doi: 10.1016/S0140-6736(11) 60054-8.

28. Brasil. E-gestor-Atenção Básica. Cobertura de saúde bucal. $<$ https://egestorab.saude.gov.br/paginas/acessoPublico/ relatorios/relHistoricoCoberturaSB.xhtml $>$.

29. Santos RS, Magalhaes BG, Goes PSA, Rocha RAC, Gaspar GS. Use of dental services in areas covered by the Family Health Strategy in Olinda, Brazil. Cad Saude Colet 2014; 22: 40-45, doi: 10.1590/1414-462X201400010 007.

30. Silva MCB, Silva RA, Ribeiro CC, Nogueira da Cruz MC. Profile of public dental care for children and adolescents in São Luís, Maranhão State [in Portuguese]. Cien Saude Colet 2007; 12: 1237-1246, doi: 10.1590/S1413-81232007000500021.

31. Estatísticas. Conselho Federal de Odontologia. <http://cfo. org.br/website/estatisticas/quantidade-geral-de-entidadese-profissionais-ativos/>

32. Aiser A. Public health insurance, program take-up and child health. Rev Econom Statis 2007; 89: 400-415, doi: 10.1162/ rest.89.3.400.

33. Schroth RJ, Boparai G, Boparai M, Zhang L, Svitlica M, Jacob $L$, et al. Tracking early visits to the dentist: a look at the first 3 years of the Manitoba Dental Association's Free First Visit program. J Can Dent Assoc 2015; 81: f8.

34. Sanguida A, Vinothini V, Prathima GS, Santhadevy A, Premlal K, Kavitha M. Age and reasons for first dental visit and knowledge and attitude of parents toward dental procedures for Puducherry children aged 0-9 years. J Pharm Bioallied Sci 2019; 11: S413-S419, doi: 10.4103/ JPBS.JPBS 54 19.

35. Mika A, Mitus-Kenig M, Zeglen A, Drapella-Gasior D, Rutkowska K, Josko-Ochojska J. The child's first dental visit. Age, reasons, oral health status and dental treatment needs among children in southern Poland. Eur J Paediatr Dent 2018; 19: 265-270, doi: 10.23804/ejpd.2018.19.04.3.

36. Ismail A, Lim S, Sohn W, Willem JM. Determinants of early childhood caries in low-income African American young children. Pediatr Dent 2008; 30: 289-296.

37. Gorman BJ, Braverman J. Family structure differences in health care utilization among US children. Soc Sci Med 2008; 67: 1766-1775, doi: 10.1016/j.socscimed.2008.09.034.

38. Ola D, Gamboa ABO, Folayan MO, Mercenes W. Family structure, socioeconomic position and utilization of oral health services among Nigerian senior secondary school pupils. J Public Health Dent 2013; 73: 158-165, doi: 10. 1111/j.1752-7325.2012.00362.x.

39. Listl S. Family composition and children's dental health behavior: evidence from Germany. J Public Health Dent 2011; 71: 91-101, doi: 10.1111/j.1752-7325.2010.00205.x.

40. Ribeiro VS, Figueiredo FP, Silva AAM, Batista RLF, Barbieri $\mathrm{MA}$, Lamy FF, et al. Do socioeconomic factors explain why maternal smoking during pregnancy is more frequent in a more developed city of Brazil? Braz J Med Biol Res 2007; 40: 1203-1210, doi: 10.1590/S0100-879X20060050 00146 . 